\title{
The design of ibuprofen-loaded microbeads using polymers obtained from Xanthosoma sagittifolium and Dillenia indica
}

\author{
Tolulope Omolola Ajala ${ }^{1, A-F}$, Boladale Olanrewaju Silva ${ }^{2, A, C, E, F}$ \\ ${ }^{1}$ Department of Pharmaceutics and Industrial Pharmacy, Faculty of Pharmacy, University of Ibadan, Nigeria \\ ${ }^{2}$ Department of Pharmaceutics and Industrial Pharmacy, Faculty of Pharmacy, University of Lagos, Akoka, Nigeria \\ A - research concept and design; $\mathrm{B}$ - collection and/or assembly of data; $\mathrm{C}$ - data analysis and interpretation; \\ $D$ - writing the article; $E$ - critical revision of the article; $F$ - final approval of the article
}

Address for correspondence

Tolulope Omolola Ajala

E-mail: tolulola1721@gmail.com

Funding sources

None declared

\section{Conflict of interest}

None declared

\section{Acknowledgements}

The authors hereby acknowledge the contribution of Fidson Healthcare Ltd., Ota, Nigeria, for the gift of ibuprofen used in the study. Bentos Pharmaceutical Industry Ibadan, Nigeria, is also acknowledged for the use of their dissolution apparatus and laboratory space for the study.

Received on January 3, 2020

Reviewed on April 22, 2020

Accepted on May 4, 2020
Cite as

Ajala TO, Silva BO. The design of ibuprofen-loaded microbeads using polymers obtained from Xanthosoma sagittifolium and Dillenia indica. Polim Med. 2020;50(1):21-31.

doi:10.17219/pim/122015

DOI

10.17219/pim/122015

\section{Copyright}

๑) 2020 by Wroclaw Medical University This is an article distributed under the terms of the Creative Commons Attribution 3.0 Unported (CC BY 3.0) (https://creativecommons.org/licenses/by/3.0/)

\begin{abstract}
Background. Ibuprofen is used both for acute and chronic disorders, such as ankylosing spondylitis, osteoarthritis and rheumatoid arthritis; however, ibuprofen causes gastrointestinal disturbances. Therefore, it would be desirable to design it as a sustained-release preparation.
\end{abstract}

Objectives. To design ibuprofen microbeads using polymers obtained from Xanthosoma sagittifolium starch and Dillenia indica mucilage to provide sustained-release delivery of ibuprofen.

Material and methods. The polymers were extracted using standard methods and characterized by their material, physicochemical, elemental, and rheological profiles. Microbeads loaded with ibuprofen were prepared using the ionotropic gelation method utilizing blends of the polymers and sodium alginate. The microbeads were evaluated using particle shape, particle size, swelling index, entrapment efficiency, and release assays.

Results. The results showed that the polymers have distinct material and physicochemical properties unique to their botanical sources. The microbeads were spherical and free-flowing, and they rolled without friction. The swelling properties ranged from $47.62 \pm 2.74 \%$ to $79.49 \pm 3.66 \%$. The particle size of the microbeads ranged from $88.14 \pm 68.57 \mu \mathrm{m}$ to $214.90 \pm 66.95 \mu \mathrm{m}$, while the encapsulation efficiencies ranged from $20.67 \pm 4.66 \%$ to $83.61 \pm 6.35 \%$. The dissolution times suggested that the concentration of the natural polymers in the bead formulation could be used to modulate the dissolution properties. Generally, formulations containing the mucilage yielded higher dissolution times than those containing the starch. The kinetics of drug release from the microbeads containing the polymer blends generally fitted the Korsmeyer-Peppas model. The highest similarity was found between formulations C 6 and D4 with f2 of 81.07 .

Conclusions. The microbeads prepared with polymers obtained from Xanthosoma and Dillenia showed acceptable physicochemical properties, dependent upon polymer type, blend and concentration.

Key words: polymers, sodium alginate, ibuprofen microbeads, Xanthoxylum sagittifolium starch, Dillenia indica mucilage 


\section{Introduction}

The oral route of drug administration constitutes the most convenient and preferred means of drug delivery into the systemic circulation. This is due to the ease of administration, the higher patient acceptance, adherence and compliance to medication, and the costeffective manufacturing process. ${ }^{1}$ Tablets and capsules are the most common oral dosage forms and are mostly prepared for immediate release, which enables rapid absorption. ${ }^{2}$ Nonetheless, drugs with a low therapeutic index are prone to eliciting adverse effects because of fluctuating drug levels. In addition, drugs with a short half-life need to be frequently administered, which affects patient adherence and overall compliance to the treatment regimen.

The production of polymeric gel beads is a novel approach for achieving the controlled release of many therapeutic agents. ${ }^{3}$ Microbeads are free-flowing and roll without friction, thus ensuring a dust-free environment during processing, in addition to a constant release rate for active agents embedded in the core. ${ }^{5}$ Beads are discrete, spherical microcapsules that serve as a solid substrate; the drug is coated on this substrate or encapsulated within the core. Microbeads provide sustained-release properties and more uniform distribution of drugs within the gastrointestinal tract and enhance drug bioavailability. They are also called microspheres and described as carrier-linked drug delivery systems, in which particle size ranges from $1 \mu \mathrm{m}$ to $1000 \mu \mathrm{m}$ and the active drug is embedded in the core and coated at the outer layers with polymers. Microspheres can be described as structures made up of a continuous phase of 1 or more miscible polymers in which drug particles are dispersed at the molecular or macroscopic level. Microspheres constitute an important part of particulate drug delivery systems by virtue of their small size and efficient carrier capacity. Thus, drugs embedded in the microsphere matrix are released at a slow, constant and controlled rate; therefore, they are capable of being used for targeted delivery. The size, surface charge and surface hydrophilicity of microspheres have all been found to be important in determining the fate of the particles in vivo. ${ }^{4}$ The use of small and round microbeads of the same size nullifies the disadvantages that are encountered with powders and granules.

Ibuprofen is widely known as a first-line non-steroidal anti-inflammatory drug (NSAID) for rheumatoid arthritis and chronic arthropathies. It also has an analgesic property and a mild antipyretic action. It acts mainly by inhibiting prostaglandin synthesis, reducing the production of pro-inflammatory cytokines such as interleukin $1 \beta$ (IL-1 $\beta)$ and tumor necrosis factor $\alpha$ (TNF- $\alpha)$. It inhibits the lipoxygenase pathway, leading to a decrease in the production of leukotrienes by the leukocytes and the synovial cells. Furthermore, it masks the T cells, thereby suppressing the production of rheumatoid factors.
It is more active than indomethacin, naproxen and other NSAIDs. This drug is indicated for the relief of mild to moderate pain and inflammation in conditions such as dysmenorrhea, migraine, and postoperative and dental pain. In these disorders, an immediately available dose is required. Ibuprofen is also used in chronic disorders - such as ankylosing spondylitis, osteoarthritis and rheumatoid arthritis - for which a sustained release is desirable. The most frequent adverse effect occurring with ibuprofen is gastrointestinal disturbance; peptic ulceration, gastrointestinal bleeding, nausea, dyspepsia, dizziness, and unexplained rash have also been reported. ${ }^{6}$ Low single-dose administration of ibuprofen and its short half-life in plasma (about 1.8-2.0 h) make it a very good candidate for the formulation of controlledrelease, multiple-unit dosage forms.

Dillenia indica L. is a large evergreen shrub native to southeastern Asia, India, Bangladesh, and Sri Lanka. ${ }^{7}$ The common English name is elephant apple or Indian catmon. Its characteristic fruits are large, round and greenish yellow, have many seeds and are edible. ${ }^{7}$ The fruit pulp is bitter-sour and is used in curries, jams and jellies in India. It is often mixed with coconut and spices to make chutneys. The leaf, bark and fruit of this plant are traditionally used as medicine in different forms for their therapeutic value, such as their antidiabetic, antioxidant and antimicrobial properties. ${ }^{8,9}$ The mucilage of the fruit is used to wash hair and has a conditioning effect. ${ }^{10}$ There is potential to exploit the usefulness of Dillenia mucilage in microbead formulation, thus harnessing its potential as a pharmaceutical drug carrier. Cocoyam (Xanthosoma sagittifolium L. Schott) contains between 22\% and $40 \%$ of starch, which is an essential component of food, providing about $60-70 \%$ of the daily caloric intake of humans. ${ }^{11}$ Cocoyam starches are used as fillers in biodegradable plastics, as well as in aerosols because of their small size. ${ }^{12}$ Despite the usefulness of cocoyam starch, it has remained largely underutilized, especially in different industrial applications.

The focus of the study, therefore, was to develop ibuprofen as microbeads using polymers obtained from Dillenia indica and Xanthoxylum sagittifolium. It is hoped that the ibuprofen microbeads will enable the administration of the drug as a controlled-release oral preparation which will protect the gastric mucous membrane from drug irritation, mask its unpleasant taste, avoid premature release in the gastrointestinal tract, reduce the frequency of administration, enhance patient compliance, minimize total drug quantity, improve bioavailability, prevent fluctuation in drug levels, and reduce the incidence of gastrointestinal disturbances. The use of natural polymers obtained from renewable resources will also aid in the development of local industries if those materials are eventually found to be acceptable. In the present study, therefore, an ibuprofen microbead was designed using polymers obtained from Dillenia indica and Xanthoxylum sagittifolium. 


\section{Material and methods}

\section{Material}

The materials used were: sodium alginate (Carl Roth GmbH \& Co, Karlsruhe, Germany), calcium acetate (Alfa Aesar GmbH \& Co, Karlsruhe, Germany); potassium dihydrogen phosphate (Lab Tech Chemicals, Windsor, Australia), disodium hydrogen dodecahydrate (Hopkin and Williams, Essex, UK), sodium hydroxide pellets (Lab Tech Chemicals), xylene (BDH Chemicals Ltd., Poole, UK), and ibuprofen (Fidson Healthcare Plc, Ota, Nigeria). All other reagents were of analytical grade. The tubers of Xanthosoma sagittifolium (cocoyam) were procured from a local market in Ibadan, in the southwestern part of Nigeria, while the Dillenia indica fruits were obtained from the botanical garden of the University of Ibadan, Nigeria.

\section{Extraction and purification of polymers}

\section{Preparation of Xanthosoma starch}

The Xanthosoma starch was extracted from mature tubers according to an established procedure. The cocoyam tubers were peeled, cut into pieces, washed, weighed $(10.0 \mathrm{~kg})$, and soaked in distilled water containing sodium metabisulfite for $24 \mathrm{~h}$ to encourage softening. The mass was then reduced to a fine pulp through wet milling using a milling machine (GEC Machines Ltd., Blackheath, UK). The fine pulp was passed through a muslin cloth to remove all debris and fibers, resulting in a milky liquid. This liquid was washed several times with distilled water and sieved through a 250-micrometer mesh sieve. The washing was continued until the supernatant no longer tested positive in an acidity test. The starch was dried at $50^{\circ} \mathrm{C}$ for $18 \mathrm{~h}$. The dried starch was powdered in a laboratory mill, passed through a 125 -micrometer mesh sieve, and weighed before being packaged in an airtight container and stored at room temperature.

\section{Preparation of Dillenia mucilage ${ }^{13}$}

Fruits of Dillenia indica were cut open and the inner part containing the mucilaginous material was scooped out and soaked for $24 \mathrm{~h}$ in chloroform water. It was strained through a muslin cloth to remove extraneous materials and then precipitated using ethanol (96\% v/v). The precipitated mucilage was filtered and washed with diethyl ether before being dried at $50^{\circ} \mathrm{C}$ for $48 \mathrm{~h}$. It was pulverized and kept in airtight containers.

\section{Determination of particle size for polymers}

The particle sizes were measured using an optical microscope fitted with a camera and Motic MC 1000 computer software (Motic China Group Co. Ltd., Xiamen, China). One hundred particles were measured and the mean size was calculated.

\section{Determination of particle density}

The particle densities were determined using a pycnometer with xylene as the displacement fluid. An empty 50-milliliter pycnometer was weighed (W), then filled with xylene; the excess fluid was wiped off and the full bottle was weighed $\left(\mathrm{W}_{1}\right)$. The difference between $\mathrm{W}_{1}$ and $\mathrm{W}$ was recorded as $\mathrm{W}_{2}$. A two-gram sample was weighed $\left(\mathrm{W}_{3}\right)$ and transferred into the full pycnometer. The excess solvent was wiped off and the bottle was weighed again $\left(\mathrm{W}_{4}\right)$. The particle density (pt) in $\mathrm{g} / \mathrm{cm}^{3}$ was then calculated using Equation 1:

$$
\text { particle density }=\frac{W_{2} * W_{3}}{50\left\{\left(W_{3}-W_{4}\right)+\left(W_{2}-W_{1}\right)\right\}}
$$

\section{Determination of ash content}

A porcelain crucible was washed and dried in an oven. It was then allowed to cool in a desiccator before being weighed. The dried polymer material was weighed into the empty crucible. The material was ignited over a low flame in the fume cupboard to char the organic matter. The crucible was then placed in a muffle furnace maintained at $600^{\circ} \mathrm{C}$ for $6 \mathrm{~h}$. On removal from the furnace, the crucible was transferred into a desiccator, cooled and weighed immediately. The percentage of ash content was calculated using Equation 2:

ash content $(\%)=\frac{(\text { weight of crucible }+ \text { ash })-(\text { weight of empty crucible }) \times 100}{\text { sample weight }}$

\section{Crude fat analysis}

Each thimble was loaded with about $3 \mathrm{~g}$ of the starch sample and plugged with cotton wool. ${ }^{14}$ The thimbles were dried and then inserted into a Soxtec ${ }^{\mathrm{TM}} \mathrm{HT}$ device (Foss, Hilleroed, Denmark) and extracted for $15 \mathrm{~min}$ in the "boiling" position, then for $45 \mathrm{~min}$ in the "rising" position. The solvent was then evaporated and the cups were released and dried at $100^{\circ} \mathrm{C}$ for $30 \mathrm{~min}$. After this, the cups were cooled in a desiccator and weighed. The same procedure was repeated for the mucilage and the fat content was calculated using Equation 3,

$$
\text { fat content }(\%)=\frac{\left(W_{3}-W_{2}\right)}{W_{1}} \times 100
$$

where $W_{3}=$ the weight of the cup with the extracted fat $W_{2}$ = the weight of the empty cup

$W_{1}=$ the weight of the sample.

\section{Determination of crude protein content}

The dried starch sample ( $1 \mathrm{~g})$ was weighed into a digestion tube and $15 \mathrm{~mL}$ of concentrated sulfuric acid was added to it. Seven Kjeldahl catalyst tablets were added into the tube which was pre-set at $410^{\circ} \mathrm{C}$. It was then digested for $45 \mathrm{~min}$ until there was a clear solution. 
The tube was placed in the distillation unit and $50 \mathrm{~mL}$ of $40 \%$ sodium hydroxide solution was dispersed into it. The digest was distilled into $25 \mathrm{~mL}$ of $4 \%$ boric acid for $5 \mathrm{~min}$. The distillate was titrated against $0.47 \mathrm{M}$ hydrochloric acid until a grey color was obtained.

$\%$ crude protein $=\%$ total nitrogen $\times$ conversion factor

\section{Determination of swelling index}

The starch or mucilage was transferred to a 100-milliliter cylinder (V1), $90 \mathrm{~mL}$ of distilled water was added, and the slurry was shaken for 5 min and then topped up to $100 \mathrm{~mL}$. The suspension was allowed to stand for $24 \mathrm{~h}$ and the sedimentation volume (V2) was measured. The swelling index was calculated using Equation 5:

$$
\text { Swelling index }=\frac{V_{2}-V_{1}}{V_{1}} \times 100
$$

\section{Solubility}

Starch/mucilage $(1 \mathrm{~g})$ was weighed (W) into a 150-milliliter conical flask. Distilled water $(15 \mathrm{~mL})$ was added and the mixture shaken for $5 \mathrm{~min}$, then placed into a heated water bath and kept at $80^{\circ} \mathrm{C}$ for $40 \mathrm{~min}$ with constant stirring. The starch slurry was then transferred into a pre-weighed centrifuge tube (W1); $7.5 \mathrm{~mL}$ of distilled water was added and the slurry centrifuged at $2200 \mathrm{rpm}$ for $20 \mathrm{~min}$. The supernatant was carefully decanted into a tarred dish (W2) and dried at $100^{\circ} \mathrm{C}$ to a constant weight (W3), then it was cooled in a desiccator. The solubility was calculated using Equation 6:

$$
\text { Solubility }(\%)=\frac{\left(W_{2}-W_{3}\right)}{W_{1}} \times 100
$$

\section{Water absorption capacity}

To each 1-gram sample, $15 \mathrm{~mL}$ of distilled water was added in a weighed 25 -milliliter centrifuge tube. The tube was agitated in a vortex mixer for $2 \mathrm{~min}$ and centrifuged at $4000 \mathrm{rpm}$ for $20 \mathrm{~min}$. It was then decanted and the clear supernatant discarded. The residue was weighed (W1). The adhering droplets of water were removed by drying the residue at $60^{\circ} \mathrm{C}$ to a constant weight (W2). The water absorption capacity (WAC) was then calculated as the weight of water bound by $100 \mathrm{~g}$ of dry powder.

\section{Fourier-transform infrared spectroscopy}

The Fourier-transform infrared (FTIR) spectra were recorded on the polymer samples prepared in potassium bromide (KBr) discs using an FTIR system (Spectrum BX 273; PerkinElmer, Waltham, USA). The scanning range was $350-4400 \mathrm{c}^{-1}$.

\section{Preformulation studies}

Preformulation studies were carried out in order to optimize the formulation and physicochemical properties of the microbeads. Several formulation trials were carried out using varying concentrations $(5 \%, 7.5 \%$ and $10 \% \mathrm{w} / \mathrm{v}$ ) of the extracted polymers alone. The polymers alone did not form discrete beads, and the few which did form could not retain their integrity outside the chelating agents. Thus, various polymer blends consisting of different ratios of natural polymers and sodium alginate were used, as shown in Table 4.

\section{Preparation of microbeads}

Ibuprofen microbeads were prepared from the hot gel blend $\left(90^{\circ} \mathrm{C}\right)$ of natural polymer and sodium alginate using the ionotropic gelation method. ${ }^{15}$ The natural polymer and sodium alginate were blended in order to obtain a total polymer concentration of $2 \% \mathrm{w} / \mathrm{v}$ at ratios of $1: 1,1: 2,1: 3,1: 4,2: 1,3: 1$, and 4:1. An appropriate quantity of the drug $(1 \mathrm{~g})$ was added, such that the ratio of total polymer to drug was $2: 1$. The resulting dispersion was extruded using a syringe with a 0.90-millimeter needle at a dropping rate of $2 \mathrm{~mL} / \mathrm{min}$ into a calcium acetate solution $(10 \% \mathrm{w} / \mathrm{v})$ maintained under agitation at $300 \mathrm{rpm}$ using a magnetic stirrer (Talboys Laboratory Stirrer Model No. 102; Troemner, Thorofare, USA). The formed beads were allowed to cure for $30 \mathrm{~min}$ and were then left standing for another $30 \mathrm{~min}$. The beads were collected by decanting, washed repeatedly with distilled water, and then dried for $24 \mathrm{~h}$ in a hot-air oven (Gallenkamp BS 250 Oven; Riley Industries Ltd, West Midlands $\mathrm{UK})$ at $40^{\circ} \mathrm{C}$.

\section{Size and morphology of beads}

The particle sizes of the microbeads were determined using the optical microscopy method. The particle sizes of 100 prepared microbeads were determined with optical microscopy using a light microscope (Leitz Laborlux II; Leica Microsystems, Wetzlar, Germany). The shape of the beads was also determined using light microscopy.

\section{Swellability of beads}

In order to determine the swellability, $100 \mathrm{mg}$ of microbeads was soaked in $20 \mathrm{~mL}$ of phosphate buffer ( $\mathrm{pH}$ 6.8) for $3 \mathrm{~h}$. The microbeads were then removed and excess buffer was wiped away using a dry filter paper; the final weight of microbeads was determined. The swollen microbeads were handled carefully in order to avoid any loss of mass due to erosion. The experiment was repeated after $6 \mathrm{~h}$ and $24 \mathrm{~h}$. Swellability - otherwise known as the swelling index - was computed using Equation 7, 


$$
\text { swelling index }(\%)=\frac{C}{I} \times 100
$$

where $C$ is the weight gain and $I$ is the initial weight of the microbeads.

\section{Entrapment efficiency}

The ibuprofen microbeads (50 mg) were accurately weighed and crushed in a glass mortar and suspended in $10 \mathrm{~mL}$ of phosphate buffer ( $\mathrm{pH}$ 6.8) with intermittent stirring. After $24 \mathrm{~h}$, the solution was filtered. The filtrate was appropriately diluted using phosphate buffer ( $\mathrm{pH}$ 6.8) and analyzed spectrophotometrically at $225 \mathrm{~nm}$ with a UV/VIS spectrophotometer (LAMBDA 12; Perkin Elmer GmbH, Rodgau, Germany). The drug entrapment efficiency (E) was calculated as in Equation 8,

$$
E(\%)=\frac{A}{T} \times 100
$$

where $\mathrm{A}$ and $\mathrm{T}$ are the actual and theoretical contents of ibuprofen, respectively.

\section{Drug release study}

The drug release behavior of the microbeads was evaluated in $900 \mathrm{~mL}$ of phosphate buffer ( $\mathrm{pH}$ 6.8) maintained at $37 \pm 0.5^{\circ} \mathrm{C}$ using the paddle method (USP XXI), rotated at $100 \mathrm{rpm}$. Samples $(10 \mathrm{~mL})$ were withdrawn at different time intervals and replaced with an equal amount of fresh medium. The amount of ibuprofen released was determined at a wavelength of $225 \mathrm{~nm}$ using a UV/visible spectrophotometer (LAMBDA 12). Measurements were done in triplicate.

\section{Modeling of release profile}

Data obtained from in vitro release studies were used in various kinetic equations to determine the kinetics and mechanism of drug release from the microbeads. The results of the drug release for the formulation was fitted to zero order, first order, Higuchi, Hixson-Crowell, Korsemeyer-Peppas, and Hopfenberg equations. ${ }^{16-19}$ The model of best fit was identified by comparing the values of correlation coefficients.

\section{Data presentation and analysis}

The experiments were conducted in triplicate and the mean determined. Statistical analysis was carried out using analysis of variance in GraphPad Prism v. 4.0 (GraphPad Software Inc., San Diego, USA) to compare the differences between formulations. The similarity factor $\left(f_{2}\right)$ was used to determine whether formulations prepared using the extracted polymers were similar to those prepared using the standard polymer sodium alginate. A p-value $\leq 0.05$ was considered statistically significant.

\section{Results and discussion}

\section{Material and physicochemical properties of the polymers}

The material and physicochemical properties of Xanthosoma sagittifolium starch and Dillenia indica mucilage are presented in Table 1. It includes values for $\mathrm{pH}$, moisture content, solubility, water absorption capacity, swelling index, crude protein, fat, ash and carbohydrate contents, density values, and flow parameters. There were distinct differences between the starch and mucilage, though both polymers had low values of water absorption capacity. Generally, low values of this parameter indicate a compact structure of polymers ${ }^{20}$ In this study, the starch was found to be more compact than the mucilage. The starch also had low levels $(<1 \%)$ of protein fat and ash content, which implies high purity as a high ash content would imply the presence of sand. The content of these proximate parameters usually vary with the botanical source of the starch: for the mucilage, which is gummy, the protein and fat content were $>1 \%$ and the ash content was also very low. Generally, gums and mucilage have nitrogenous compounds, hence the protein. The starch had a higher carbohydrate content than the mucilage. The carbohydrate content is higher than any other proximate parameter, illustrating that they are true polysaccharides.

The $\mathrm{pH}$ of the starch was higher than that of the mucilage, but within the acceptable range for excipients used in oral formulations. It is not expected that the $\mathrm{pH}$ should be acidic, hence in terms of $\mathrm{PH}$, the polymers were acceptable. The moisture content of the mucilage was higher than that of the starch, but both were within the acceptable range to keep an excipient free of microbial growth and deterioration. The maximum water content prescribed for safe storage of starch is $13 \% \mathrm{w} / \mathrm{w}$, while pharmacopoeial limit for natural gums and mucilage is $\leq 15.0 \%$; the moisture in a material should be moderate to prevent enzymatic activation of the degradation processes. ${ }^{21}$

Table 1. Material and physicochemical properties of Xanthosoma sagittifolium starch and Dillenia indica mucilage

\begin{tabular}{|lc|c|}
\multicolumn{1}{c|}{ Parameters } & $\begin{array}{c}\text { Xanthosoma sagittifolium } \\
\text { starch }\end{array}$ & $\begin{array}{c}\text { Dillenia indica } \\
\text { mucilage }\end{array}$ \\
\hline $\mathrm{pH}$ & $6.471 \pm 0.281$ & $4.120 \pm 0.181$ \\
Moisture content [\%] & $6.011 \pm 0.005$ & $7.271 \pm 0.010$ \\
Solubility [\%] & $1.851 \pm 0.07$ & $2.462 \pm 0.101$ \\
Water absorption capacity [\%] & $8.23 \pm 0.25$ & $5.67 \pm 2.12$ \\
Swelling index [\%] & $1.172 \pm 0.112$ & $272.741 \pm 0.211$ \\
Crude protein [\%] & $0.470 \pm 0.001$ & $4.841 \pm 0.002$ \\
Fat [\%] & $0.401 \pm 0.004$ & $3.402 \pm 0.021$ \\
Ash [\%] & $0.498 \pm 0.022$ & $0.461 \pm 0.003$ \\
Carbohydrate [\%] & $91.23 \pm 1.03$ & $89.56 \pm 0.17$ \\
Particle density [g/mL] & $1.257 \pm 0.004$ & $1.358 \pm 0.023$ \\
Particle size [ $\mu \mathrm{m}]$ & $16.870 \pm 8.08$ & $47.372 \pm 5.26$ \\
\hline
\end{tabular}


The moisture content of the natural polymers used in this study was within the pharmacopoeial limits, testifying to their quality. The mucilage was more soluble than the starch, but the starch was better at binding water. The mucilage was bulkier and had denser particles than the starch, while the tapped density for the starch was higher, indicating an improved packing property over the mucilage. The mucilage has significantly larger particles $(\mathrm{p}<0.05)$.

The functional group bands of the natural polymers obtained from FTIR spectra are presented in Table 2. The characteristic functional groups are reflected from the peaks of absorbance. The different classes of functional groups present in the polymers imply that they are complex polysaccharides.

\section{Viscosity of polymer blends}

The viscosity of polymer blends is presented in Table 3 . Dillenia had higher viscosity $(52.00 \pm 0.01 \mathrm{cP})$ than Xanthosoma $(14.00 \pm 0.06 \mathrm{cP})$ at the same concentration, but the viscosity of alginate $(532.00 \pm 14.00 \mathrm{cP})$ was significantly higher $(\mathrm{p}<0.05)$ than of each of the polymers. Generally, Dillenia/alginate blends yielded significantly higher viscosities $(\mathrm{p}<0.05)$.

\section{Physicochemical properties of the microbeads}

The freshly prepared microbeads were spherical in shape, as shown in Fig. 1. Those prepared using Xanthosoma alginate blends ( $\mathrm{C} 1$ and $\mathrm{C} 4$ ) were whitish in color, while those prepared using Dillenia/alginate blends were light brown in color. The photomicrographs of the dried microbeads

Table 2. Antibacterial activity and MIC of SaZnONPs against some pathogenic bacteria

\begin{tabular}{|c|c|c|}
\hline $\begin{array}{c}\text { Wavenumber } \\
{\left[\mathrm{cm}^{-1}\right]}\end{array}$ & Class & Assignment \\
\hline \multicolumn{3}{|c|}{ Xanthosoma } \\
\hline 604 & alkynes & $\mathrm{RCH}$ \\
\hline 880 & aromatics, amines & $\mathrm{C}-\mathrm{H}$ out of plane \\
\hline 894 & alkenes & $\mathrm{R} 2 \mathrm{C}=\mathrm{CH} 2$ \\
\hline 1172 & alkyl halides & $\mathrm{R}-\mathrm{F}$ \\
\hline 1306 & carboxylic acid esters & C-O stretch \\
\hline 2950 & alkanes & $\mathrm{CH} 2 \mathrm{CH} 3$ \\
\hline 3040 & aromatics & $\mathrm{Ar}-\mathrm{H}$ \\
\hline \multicolumn{3}{|c|}{ Dillenia } \\
\hline 772 & aromatics & $\mathrm{C}-\mathrm{H}$ out of plane \\
\hline 1095 & alcohols & C-O stretch \\
\hline 1451 & alkanes & $\mathrm{CH}_{2} \mathrm{CH}_{3}$ \\
\hline 1541 & miscellaneous & $\mathrm{N}-\mathrm{H}$ out of plane \\
\hline 2705 & aldehydes & $\mathrm{RCHOC}-\mathrm{H}$ \\
\hline 3353 & carboxylic acids & dimer $\mathrm{OH}$ \\
\hline 3447 & amines & $\mathrm{N}-\mathrm{H}$ stretch \\
\hline
\end{tabular}

Table 3. The composition and viscosity of polymer blends used for the formulation of ibuprofen-loaded microbeads (mean $\pm \mathrm{SD} ; \mathrm{n}=3$ )

\begin{tabular}{|r|c|c|c|c|} 
S/N & Polymers & $\begin{array}{c}\text { Polymer } \\
\text { ratio }\end{array}$ & $\begin{array}{c}\text { Microbead } \\
\text { formulation } \\
\text { code }\end{array}$ & $\begin{array}{c}\text { Viscosity } \\
\text { [cP] }\end{array}$ \\
\hline 1 & Alginate & $1: 0$ & A1 & $532.00 \pm 4.00$ \\
3 & Xanthosoma/alginate & $1: 1$ & C1 & $666.67 \pm 15.28$ \\
4 & Xanthosoma/alginate & $1: 2$ & C2 & $763.33 \pm 15.28$ \\
5 & Xanthosoma/alginate & $1: 4$ & C4 & $896.00 \pm 4.57$ \\
6 & Xanthosoma/alginate & $2: 1$ & C5 & $520.00 \pm 4.00$ \\
7 & Xanthosoma/alginate & $3: 1$ & C6 & $470.00 \pm 17.32$ \\
8 & Xanthosoma/alginate & $4: 1$ & C7 & $372.00 \pm 4.00$ \\
9 & Xanthosoma/alginate & $1: 0$ & C8 & $14.00 \pm 0.06$ \\
10 & Dillenia/alginate & $1: 1$ & D1 & $3883.33 \pm 76.38$ \\
11 & Dillenia/alginate & $1: 2$ & D2 & $4029.33 \pm 8.33$ \\
12 & Dillenia/alginate & $1: 3$ & D3 & $4516.67 \pm 37.86$ \\
13 & Dillenia/alginate & $1: 4$ & D4 & $4856.67 \pm 40.42$ \\
14 & Dillenia/alginate & $2: 1$ & D5 & $2256.00 \pm 4.00$ \\
15 & Dillenia/alginate & $3: 1$ & D6 & $2532.00 \pm 4.00$ \\
16 & Dillenia/alginate & $4: 1$ & D7 & $2800.00 \pm 62.45$ \\
17 & Dillenia/alginate & $1: 0$ & D8 & $52.00 \pm 0.01$ \\
\hline & & & & 826.67 \\
\hline
\end{tabular}

SD - standard deviation; S/N - sample number.

are presented in Fig. 2. Generally, they were spherical and had a rough surface, possibly due to the drying procedures. The bead shape and rough surface are consistent with the findings of Akin-Ajani et al. ${ }^{22}$ who used date mucilage blended with sodium alginate to prepare beads.

The physicochemical properties and dissolution times of the microbeads are presented in Table 4. The microbeads prepared with blends of the polymers and alginate yielded a higher swelling index than the one from alginate alone. Microbeads from Xanthosoma/alginate blends resulted in a swelling index ranging between $47.62 \pm 2.74 \%$ and $60.52 \pm 5.02 \%$, while Dillenia/alginate blends yielded a $51.92 \pm 3.45 \%$ to $79.49 \pm 3.66 \%$ swelling index. This shows that Dillenia imparted higher swelling properties than Xanthosoma. Equal blends of Xanthosoma and alginate resulted in $50.17 \pm 4.91 \%$, while blends of Dillenia and alginate $(70.32 \pm 2.43 \%)$ had significantly higher swelling ( $\mathrm{p}<0.05)$. Generally, swelling increased over time, but the differences were not significant; within $3 \mathrm{~h}$, the beads would have swollen to about $90 \%$ of their capacity.

Bead size is an important parameter in the evaluation of microbeads, since the size determines where it fits within the classification. ${ }^{23}$ All the formulations were within the acceptable size range for microbeads $(1-1000 \mu \mathrm{m})$. The size of the beads prepared using Xanthosoma/alginate blends was from $88.14 \pm 68.57 \mu \mathrm{m}$ to $189.00 \pm 54.20 \mu \mathrm{m}$. The sizes increased as the concentration of alginate increased in the blends ( $\mathrm{C} 1$ to $\mathrm{C} 4)$, which was also true for beads which contained more Xanthosoma than alginate (C5 to C7). The particle size for the beads prepared using Dillenia/alginate 


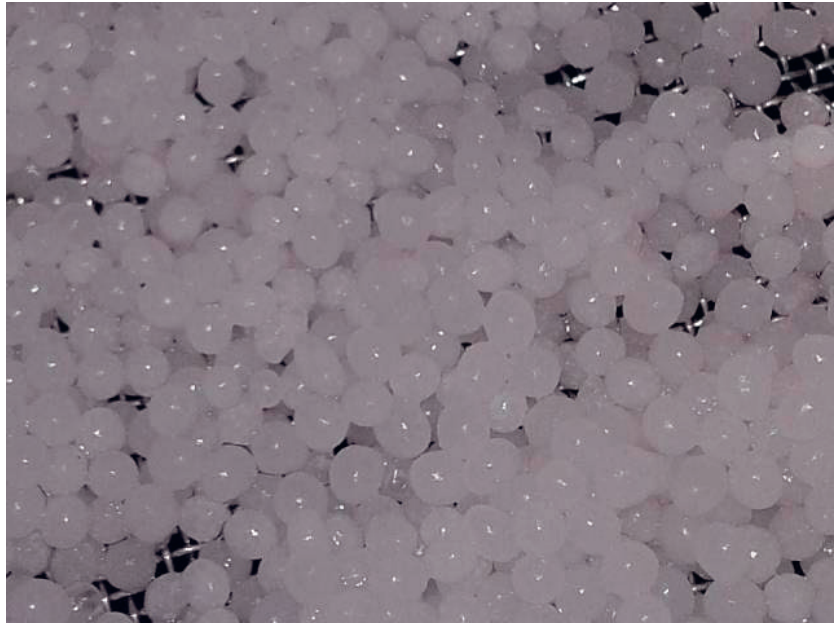

Polymer blends of Xanthosoma sagitifolium starch and sodium alginate in ratio 1:1 (C1)

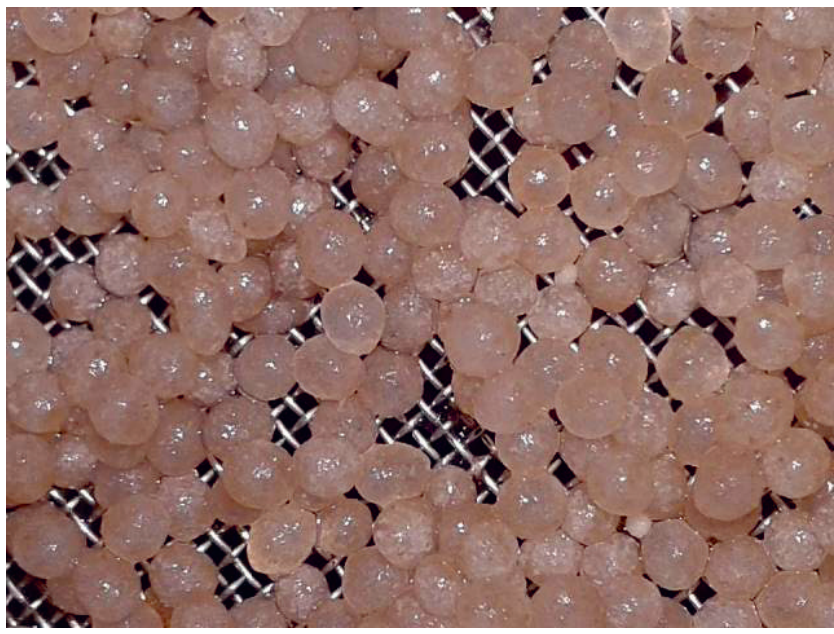

Polymer blends of Dillenia indica and sodium alginate in ratio 1:1 (D1)

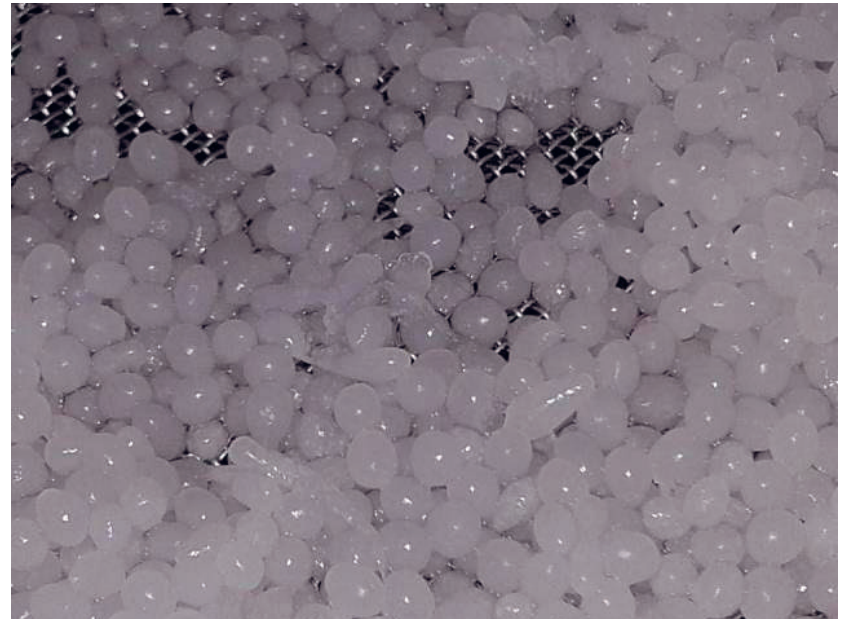

Polymer blends of Xanthosoma sagitifolium starch and sodium alginate in ratio 1:4 (C4)

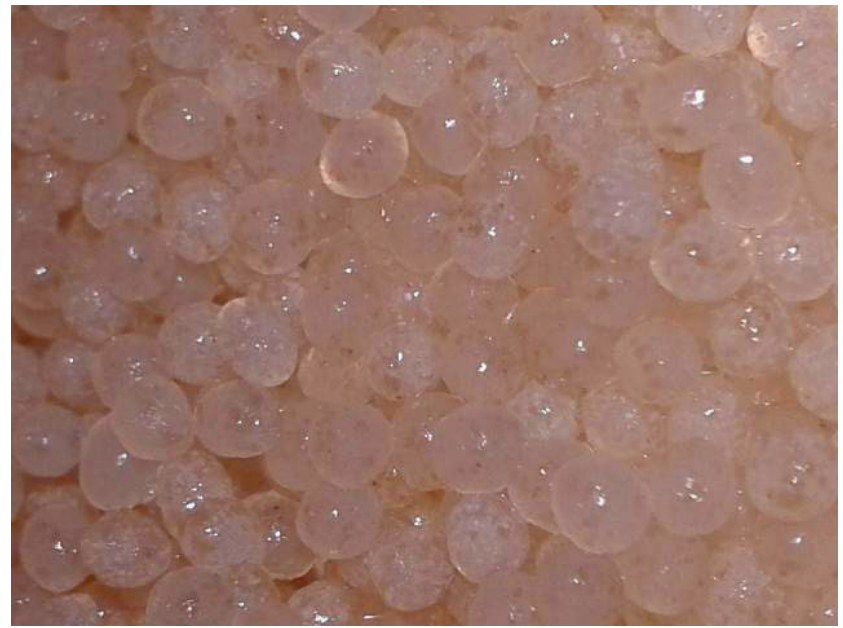

Polymer blends of Dillenia indica and sodium alginate ratio 1:3 (D3)

Fig. 1. Representative figures of freshly prepared ibuprofen-loaded microbeads using different polymer blends

Table 4. Physicochemical properties and dissolution times of ibuprofen-loaded microbeads prepared with polymer blends

\begin{tabular}{|c|c|c|c|c|c|c|}
\hline \multirow{2}{*}{$\begin{array}{l}\text { Formulation } \\
\text { code }\end{array}$} & \multicolumn{2}{|c|}{ Swelling index } & \multirow{2}{*}{$\begin{array}{c}\text { Mean particle size } \\
{[\mu \mathrm{m}]}\end{array}$} & \multirow{2}{*}{$\begin{array}{l}\text { Encapsulation efficiency } \\
{[\%]}\end{array}$} & \multicolumn{2}{|c|}{$\begin{array}{l}\text { Dissolution times } \\
\text { [min] }\end{array}$} \\
\hline & $3 \mathrm{~h}$ & $24 \mathrm{~h}$ & & & $t_{25}$ & $t_{80}$ \\
\hline $\mathrm{A} 1$ & $44.41 \pm 2.67$ & $53.49 \pm 3.78$ & $178.80 \pm 2.46$ & $57.72 \pm 3.31$ & 94.68 & 302.96 \\
\hline C1 & $50.17 \pm 4.91$ & $59.18 \pm 4.44$ & $88.14 \pm 68.57$ & $52.90 \pm 2.77$ & 84.95 & 271.84 \\
\hline$C 2$ & $47.62 \pm 2.74$ & $50.02 \pm 5.23$ & $88.37 \pm 59.74$ & $56.60 \pm 4.24$ & 77.74 & 248.77 \\
\hline $\mathrm{C} 3$ & $56.54 \pm 4.32$ & $64.22 \pm 3.45$ & $147.20 \pm 46.46$ & $64.86 \pm 5.43$ & 83.82 & 268.24 \\
\hline$C 4$ & $50.02 \pm 1.89$ & $60.98 \pm 3.08$ & $189.00 \pm 54.20$ & $71.83 \pm 5.63$ & 111.27 & 356.06 \\
\hline C5 & $52.70 \pm 3.28$ & $56.96 \pm 7.09$ & $158.23 \pm 62.81$ & $40.00 \pm 3.94$ & 107.18 & 342.99 \\
\hline C6 & $49.95 \pm 3.57$ & $57.84 \pm 6.78$ & $162.70 \pm 57.46$ & $51.96 \pm 5.22$ & 85.44 & 273.41 \\
\hline C7 & $60.52 \pm 5.02$ & $69.22 \pm 3.45$ & $183.10 \pm 46.55$ & $83.61 \pm 6.35$ & 79.38 & 254.01 \\
\hline D1 & $70.32 \pm 2.43$ & $75.09 \pm 5.62$ & $170.70 \pm 50.54$ & $69.51 \pm 5.11$ & 121.36 & 388.34 \\
\hline D2 & $57.98 \pm 5.12$ & $63.28 \pm 5.32$ & $175.10 \pm 50.06$ & $20.67 \pm 4.66$ & 76.97 & 246.29 \\
\hline D3 & $51.92 \pm 3.45$ & $57.23 \pm 4.14$ & $175.50 \pm 53.88$ & $28.13 \pm 5.39$ & 113.36 & 362.76 \\
\hline D4 & $57.36 \pm 3.62$ & $60.24 \pm 5.68$ & $190.00 \pm 66.36$ & $60.82 \pm 7.18$ & 86.70 & 277.44 \\
\hline D5 & $68.25 \pm 4.55$ & $76.77 \pm 4.65$ & $214.90 \pm 66.13$ & $52.39 \pm 3.79$ & 97.94 & 313.39 \\
\hline D6 & $79.49 \pm 3.66$ & $82.83 \pm 5.56$ & $174.11 \pm 54.92$ & $64.09 \pm 4.66$ & 128.14 & 410.05 \\
\hline D7 & $76.77 \pm 7.09$ & $78.21 \pm 5.64$ & $195.32 \pm 53.06$ & $66.07 \pm 5.35$ & 125.78 & 402.50 \\
\hline
\end{tabular}



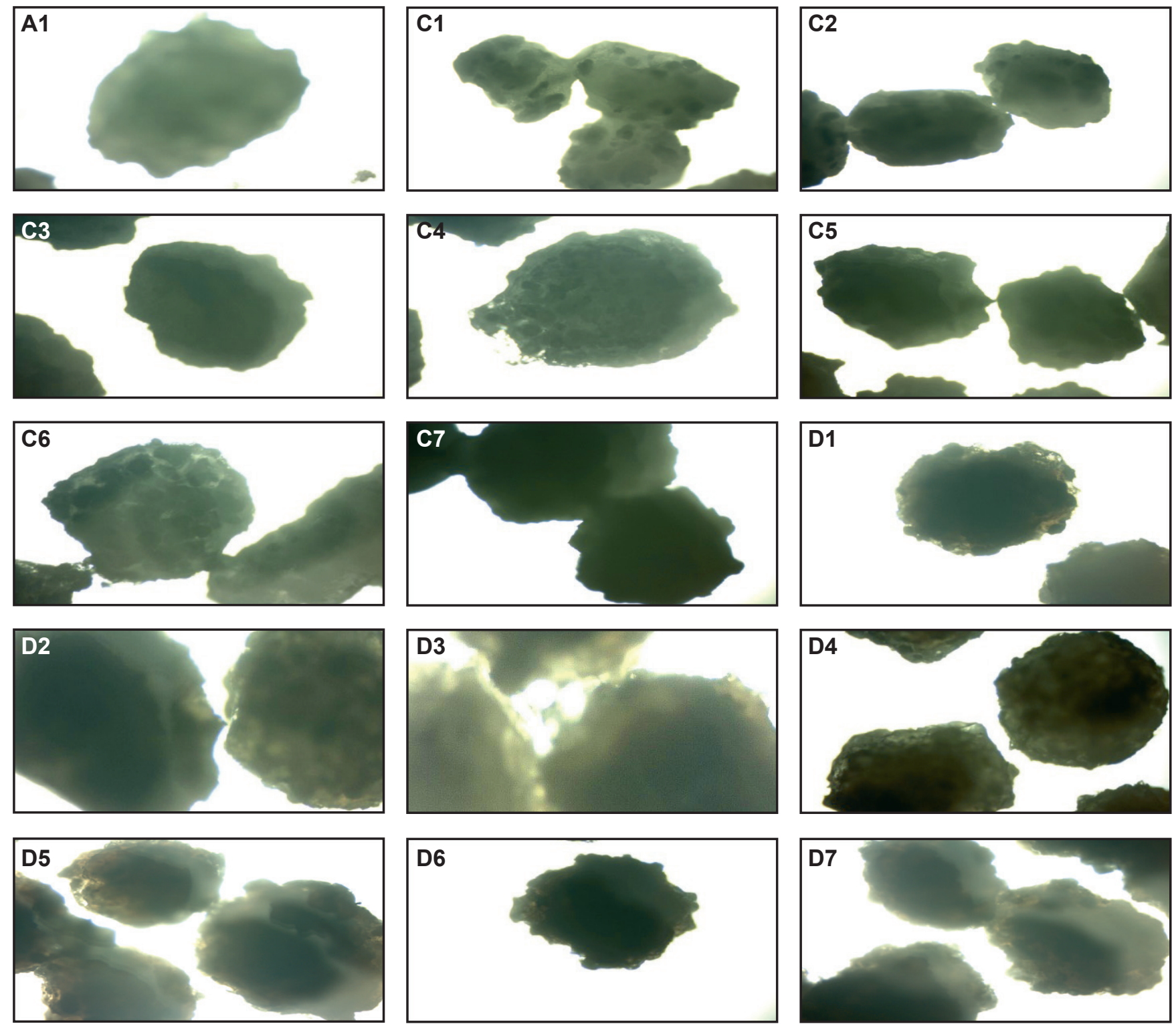

Fig. 2. Photomicrographs of ibuprofen-loaded microbeads containing polymer blends. A1 - sodium alginate only as polymer. C1-C7 - polymer blends of Xanthosoma and alginate. D1-D7 - polymer blends of Dillenia indica and alginate

blends was from $170.70 \pm 50.54 \mu \mathrm{m}$ to $214.90 \pm 66.95 \mu \mathrm{m}$. The beads were therefore larger than those prepared using Xanthosoma. The sizes also increased as the concentration of alginate increased in the blends (D1 to D4), but there was no particular trend for beads which contained more Dillenia than alginate (D5 to D7).

The range of encapsulation efficiency (EE) for beads containing Xanthosoma/alginate blends in increasing concentrations of alginate ( $\mathrm{C} 1$ to $\mathrm{C} 4$ ) was from 52.90 $\pm 2.77 \%$ to $71.83 \pm 5.63 \%$. Xanthosoma/alginate blends containing increasing amounts of Xanthosoma (C5 to C7) yielded beads with an EE range from $40.00 \pm 3.94 \%$ to $83.61 \pm 6.35 \%$. Dillenia/alginate blends with increasing concentrations of alginate (D1 to D4) resulted in EE values ranging from $20.67 \pm 4.66 \%$ to $69.1 \pm 5.11 \%$. D1, which consisted of an equal blend of Dillenia and alginate, offered the highest EE.
The microbeads from polymer blends with increasing concentrations of Dillenia (D5 to D7) yielded increasing levels of EE, ranging between $52.39 \pm 3.79 \%$ and 66.07 $\pm 5.35 \%$. This implies that for microbeads prepared using starch, the more the alginate, the higher the EE for Xanthosoma/alginate polymer blends $\mathrm{C} 1-\mathrm{C} 4$. For $\mathrm{C} 5-\mathrm{C} 7$, the $\mathrm{EE}$ increased as the concentration of starch increased. This implies that the starch and sodium alginate particles interacted in such a way that the EE of the system improved. In both directions of blending starch and sodium alginate, there was a positive outcome on the EE. For microbeads prepared using Dillenia and sodium alginate blends, formulation D1 - with an equal concentration of the polymers - offered the highest EE. As the concentration of alginate increased (D1-D4), there seemed to be no particular pattern in the EE. However, as the concentration of Dillenia increased in the polymer blend 
(D5-D7), there was a consistent increase in EE. This indicates that an increase in the amount of Dillenia in the polymer blend favored the encapsulation of ibuprofen.

\section{Drug release properties of the microbeads}

In vitro dissolution has been recognized as an important element in drug development. It can also be used as a substitute for the assessment of bio-equivalence. The mechanism of drug release is affected by the properties of the core materials, including solubility, diffusibility and partition coefficient. ${ }^{24}$ In addition, diffusion-controlled drug release occurs where the drug molecules are uniformly dispersed within the polymer. ${ }^{25}$ The release profiles of ibuprofen from the microbead formulations in Fig. 3 demonstrate a moderate release over time. Formulation $\mathrm{C} 4$ from a Xanthosomal alginate blend ratio of $1-4$ (i.e., 20\% starch), formula D1 from a Dillenia/alginate blend ratio of 1:1 (50\% mucilage) and formulation A1 (100\% sodium alginate) all exhibited a gradual release over time and were considered to deliver optimum properties in this regard. In controlled release formulations, it is not desirable that an initial high rate of drug release - usually referred to as "burst release" (a situation in which 15\% of a drug is released within the $1^{\text {st }}$ hour) - should occur. This allows for avoiding adverse drug effects and the possibility of rendering the delivery system ineffective. ${ }^{26}$ In formulations C4, D1 and A1, the release profiles show that the embedded drugs were not loosely bound to the surface of the beads, hence the gradual release.

The dissolution times shown in Table 4 for microbeads prepared with starch in alginate polymer blends demonstrate that the concentration of the natural polymers could be used to modulate the dissolution properties from the microbead formulations. Generally, as alginate increased in the starch/alginate blends (1:2 to $1: 4)$, the dissolution times for ibuprofen release increased, show- ing that delayed release properties were conferred onto the formulation. However, equal quantities of starch and alginate (1:1) did not follow this pattern in the blends, as its dissolution times resembled a 1:3 ratio. Thus, the ranking of dissolution times among the microbead formulations of starch/alginate blends containing increasing alginate quantity was $\mathrm{C} 4>\mathrm{C} 1>\mathrm{C} 3>\mathrm{C}>\mathrm{C} 2$.

Formulations $\mathrm{C} 5-\mathrm{C} 7$ contained increasing quantities of the starch, and the dissolution times from these blends reduced as the starch concentration increased. This suggests that larger concentrations of the starch may not confer delayed release properties as much as the other concentrations. For delayed release properties, formula $\mathrm{C} 4$ produced the longest dissolution times $-25 \%$ of the drug was released in nearly $2 \mathrm{~h}$ and $80 \%$ was released in approx. $6 \mathrm{~h}$; these dissolution times were much longer than those of formulations prepared using alginate alone. The presence of starch modified the dissolution times which the alginate provided to the microbeads.

Generally, formulations containing the mucilage and alginate blends yielded longer dissolution times compared to those containing the starch. The dissolution times of microbeads prepared with blends of mucilage and alginate in increasing alginate concentrations (1:1 to $1: 4$ ) were ranked as follows: D1 > D3 > D4 > D2. As with the starch/alginate blends, a 1:2 ratio produced the shortest dissolution times. A 1:1 mucilage/alginate blend yielded the longest dissolution times, whereas with the starch 1:4 was the longest. Formula D1 yielded dissolution times of over $2 \mathrm{~h}$ for a release of $25 \%$ and almost $6.5 \mathrm{~h}$ for $80 \%$ drug release. The ranking of dissolution times for formulations obtained from mucilage/alginate blends with increasing concentrations of mucilage (2:1 to 4:1 ratios) was D6 > D7 > D5. This shows that a 3:1 ratio produced microbeads with the slowest release, thus conferring better delayed-release properties on the formulations.

In terms of dissolution times, formula D6 containing a 3:1 mucilage/alginate blend provided optimal values: $25 \%$ drug release was achieved in over $2 \mathrm{~h}$, while $80 \%$
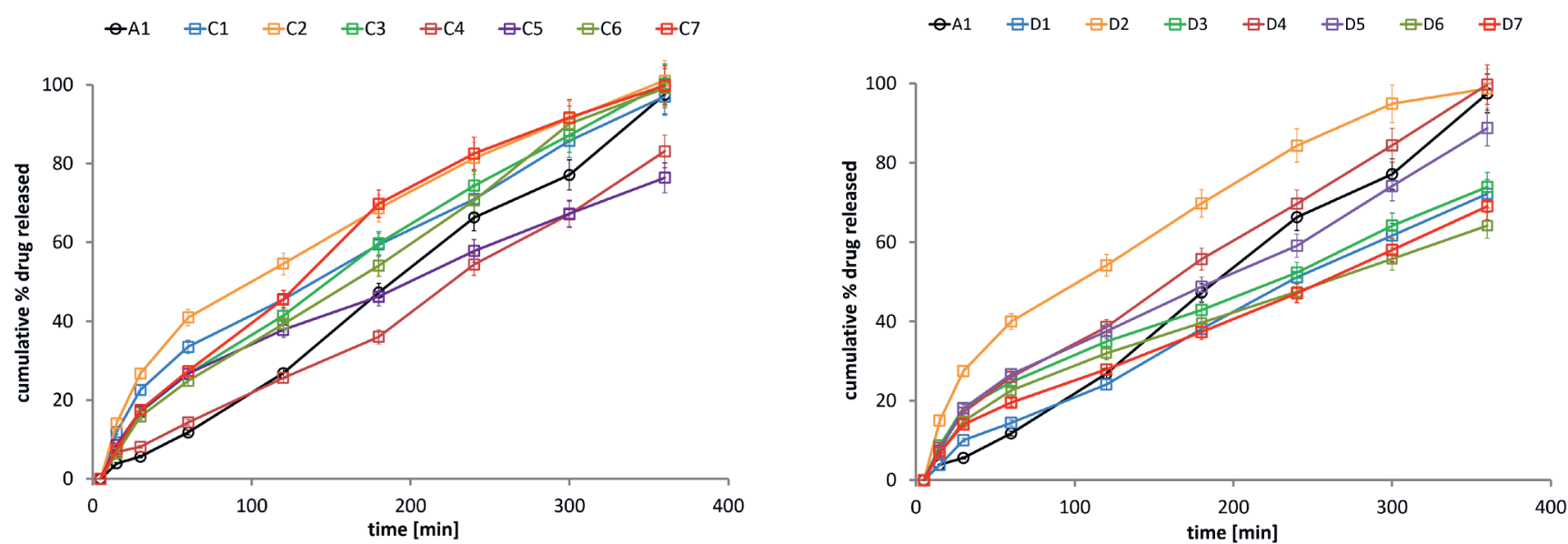

Fig. 3. Dissolution profiles of ibuprofen-loaded microbeads prepared with polymer blends. A1 - sodium alginate only as polymer. C1-C7 - polymer blends of Xanthosoma and alginate. D1-D7 - polymer blends of Dillenia indica and alginate 
was released after nearly $7 \mathrm{~h}$. These results are comparable to the studies of Odeku et al. on the design of microbeads using 4 natural gums. ${ }^{26}$ Their report showed that the dissolution times of beads containing natural gums (irvingia, khaya and cissus) were longer at a ratio of 3:1 for natural gum/alginate blends. In the current study, Dillenia mucilage seemed to follow the pattern of 3 of the natural gums.

The kinetics of drug release is important due to its influence on drug bioavailability, dosage intervals, and the occurrence of toxicity or unwelcome side effects. ${ }^{24}$ The correlation coefficients obtained from fitting the release data to different kinetic models are presented in Table 5. The kinetics of drug release from the microbeads containing the polymer blends fitted the Korsmeyer-Peppas (A1, C1, C2, C3, C5, C6, and D1-D7) and Hopfenberg ( $\mathrm{C} 4$ and $\mathrm{C} 7$ ) models using correlation coefficients $\left(r^{2}=0.9902-0.9970\right)$.

The Korsmeyer-Peppas model of drug release is useful in describing the release from polymeric systems. The rate of release for the model is related to the structural and geometric properties of the drug delivery systems, in this case with the polymers serving as carriers. The model also provides a release exponent "n", which corresponds to the mechanism of the release. Generally, in this study, the drug release from the microbeads was controlled by a combination of diffusion and erosion mechanisms. The release mechanism using the $n$-value for most of the beads corresponds to mass transfer following a non-Fickian anomalous $0.5<\mathrm{n}<1.0$ diffusion. However, formula $\mathrm{C} 4$ yielded an n-value of 1.045 and A1 (made from alginate) of 1.105 , which indicates that the drug release from these microbeads was controlled by super case II transport, in which a pronounced acceleration of drug release from the microbeads occurred toward the latter stages of release, resulting in a more rapid relaxation-controlled transport. In addition, the drug release from formulations $\mathrm{C} 4$ and $\mathrm{C} 7$, prepared from Xanthosoma/alginate blends, fit the Hopfenberg model ( $r^{2}=0.9955$ and 0.9966 , respectively).

The Hopfenberg model describes the release of a drug from spherical formulations, and the mathematical model is used for correlating the drug release from a surfaceeroding polymer for as long as the surface remains constant during the degradation process. The physicochemical properties of the drug and the polymer, as well as the drug-to-polymer ratio, have been shown to govern the release of a drug from formulations, which could mean that the amount of the polymer could be used to modify the release properties of the microbeads.

\section{Conclusions}

The polymers obtained from Xanthosoma sagittifolium and Dillenia indica had different physicochemical properties, such as particle size, shape and viscosity. The ibuprofen microbeads were discrete, generally spherical and with a particle size $<250 \mu \mathrm{m}$. The bead swelling depended on the type and concentration of the natural polymer present in the polymer blend. The entrapment efficiencies for the beads ranged from $20 \%$ to $30 \%$ and the microbeads demonstrated controlled release properties. Ibuprofen microbeads were successfully formulated with properties varying according to polymer type and concentration.

Table 5. Correlation coefficients obtained for ibuprofen microbeads using different mathematical models $(n=3)$

\begin{tabular}{|c|c|c|c|c|c|c|c|}
\hline \multirow{2}{*}{$\begin{array}{l}\text { Formulation } \\
\text { code }\end{array}$} & \multirow{2}{*}{ Zero order } & \multirow{2}{*}{ First order } & \multirow{2}{*}{ Higuchi } & \multicolumn{2}{|c|}{ Korsmeyer-Peppas } & \multirow{2}{*}{ Hixson-Crowell } & \multirow{2}{*}{ Hopfenberg } \\
\hline & & & & $\overline{r^{2}}$ & $\mathrm{n}$ & & \\
\hline $\mathrm{A} 1$ & 0.9936 & 0.9257 & 0.8344 & $0.9966^{*}$ & 1.105 & 0.9529 & 0.9951 \\
\hline $\mathrm{C} 1$ & 0.9189 & 0.9724 & 0.9662 & $0.9918^{*}$ & 0.649 & 0.9736 & 0.9743 \\
\hline $\mathrm{C} 2$ & 0.8526 & 0.9788 & 0.9809 & $0.9892^{*}$ & 0.575 & 0.9720 & 0.9788 \\
\hline C3 & 0.9734 & 0.9712 & 0.9351 & $0.9974^{*}$ & 0.772 & 0.9872 & 0.9934 \\
\hline C4 & 0.9940 & 0.9494 & 0.8566 & 0.9945 & 1.045 & 0.9679 & $0.9955^{*}$ \\
\hline C5 & 0.9164 & 0.9801 & 0.9678 & $0.9926^{*}$ & 0.646 & 0.9700 & 0.9801 \\
\hline C6 & 0.9837 & 0.9584 & 0.9171 & 0.9956 & 0.828 & 0.9783 & 0.9924 \\
\hline C7 & 0.9467 & 0.9784 & 0.9427 & 0.9896 & 0.718 & 0.9936 & 0.9966 \\
\hline D1 & 0.9947 & 0.9810 & 0.8912 & $0.9970^{*}$ & 0.918 & 0.9909 & 0.9965 \\
\hline D2 & 0.8454 & 0.9803 & 0.9798 & $0.9873^{*}$ & 0.571 & 0.9759 & 0.9806 \\
\hline D3 & 0.9182 & 0.9687 & 0.9618 & $0.9878^{*}$ & 0.652 & 0.9603 & 0.9687 \\
\hline D4 & 0.9782 & 0.9635 & 0.9281 & $0.9960^{*}$ & 0.795 & 0.9799 & 0.9887 \\
\hline D5 & 0.9550 & 0.9697 & 0.9403 & $0.9885^{*}$ & 0.732 & 0.9742 & 0.9744 \\
\hline D6 & 0.9094 & 0.9704 & 0.9693 & $0.9916^{*}$ & 0.636 & 0.9569 & 0.9704 \\
\hline D7 & 0.9621 & 0.9785 & 0.9372 & $0.9902^{*}$ & 0.749 & 0.9783 & 0.9789 \\
\hline
\end{tabular}

* Highest correlation coefficient of drug release kinetics. 


\section{ORCID iDs}

Tolulope Omolola Ajala (D) https://orcid.org/0000-0002-1257-746X Boladale Olanrewaju Silva (D) https://orcid.org/0000-0003-2115-6090

\section{References}

1. Kumar KPS, Bhowmik D, Dutta A, Paswan S, Deb L. Recent trends in scope and opportunities of control release oral drug delivery systems. Pharm Sci. 2012;1(1):20-40.

2. Ajala TO, Akin-Ajani OD, Odeku OA. Recent advances in oral drug delivery systems. In: Violiani V, ed. Recent Advances in Drug Delivery Research. New York, NY: Nova Science Publishers Inc.; 2013:33-50. ISBN: 978-1-62948-228-6.

3. Chien YW. Novel Drug Delivery Systems. $2^{\text {nd }}$ ed. New York, NY: Marcel Dekker Inc.; 1992:2-38.

4. Alagusundaram M, Sudana CM, Umashankari K, Badarinath AV Lavanya C, Annamacharya RS. Microbeads as a novel drug delivery system: A review. Int J Chemtech Res. 2009;1(3):526-534.

5. Bhandari N, Pooni N, Verma P, Gupta R. Microspheres as a novel drug delivery system: A review. Int J Pharm Res Bios. 2014;3(14):489-506.

6. Devrim B, Canefe K. Preparation and evaluation of modified release ibuprofen microspheres with acrylic polymers (eudragit) by quasi emulsion solvent diffusion method: Effect of variables. Acta Pol Pharm. 2006;63(6):521-534.

7. Bose U, Gunasekaran K, Bala V, Rahman AA. Evaluation of phytochemical and pharmacological properties of Dillenia indica Linn. leaves. J Pharmacol Toxicol. 2010;5(5):222-228.

8. Pradhan BK, Badola HK. Ethnomedicinal plant use by Lepcha tribe of Dzongu valley, bordering Khangchendzonga Biosphere Reserve, in North Sikkim, India. J Ethnobiol Ethnomed. 2008:4(22):32-37.

9. Singh DR, Singh S, Salim KM, Srivastava RC. Estimation of phytochemicals and antioxidant activity of underutilized fruits of Andaman Islands (India). Int J Food Sci Nutr. 2012;63(4):446-452.

10. Sekar N, Sukumar R, Leishman M. Waiting for Gajahlan elephant mutualist's contingency plan for an endangered megafaunal disperser. J Ecol. 2013;101(6):1379-1388.

11. Chamba MB. Studies on the production and evaluation of starch from yam (Dioscorea spp.) and Cocoyam (Colocasia esculenta) tubers cultivated in Nigeria. EC Nutrition. 2016;3(2):572-588.

12. Food and Agriculture Organization of the United Nations (FAO). FAOSTAT Statistics Database - Agriculture. Rome, Italy: FAO; 2003. www.fao.org/statistics. http://www.fao.org/statistics/en/. Accessed on November 2019.
13. Akin-Ajani OD, Ajala TO, Okoli UM, Okonta O. Development of directly compressible excipients from Phoenix dactylifera (Date) mucilage and microcrystalline cellulose using co-processing techniques. Acta Pharm. Sci. 2018;56(3):3-12. doi:10.23893/1307-2080. APS.0561

14. Association of Official Analytical Chemists (AOAC). Official Methods of Analysis of Association of Official Analytical Chemists. $15^{\text {th }}$ ed. Arlington, VA: AOAC; 2000.

15. Odeku OA, Aderogba, AA, Ajala TO, Akin-Ajani OD, Okunlola A. Formulation of floating metronidazole microspheres using cassava starch (Manihot esculenta) as polymer. J Pharm Investig. 2017;47(5):445-451.

16. Singhvi G, Singh M. Review: In-vitro drug release characterization models. Int J Pharm Stud Res. 2011;2:77-84.

17. Dash S, Murthy PN, Nath L, Chowdhury P. Kinetic modeling on drug release from controlled drug delivery systems. Acta Pol Pharm. 2010;67(3):217-223.

18. Fu Y, Kao WJ. Drug release kinetics and transport mechanisms of non-degradable and degradable polymeric delivery systems. Expert Opin Drug Deliv. 2010;7(4):429-444.

19. Siepmann J, Peppas NA. Modeling of drug release from delivery systems based on hydroxypropyl methylcellulose (HPMC). Adv Drug Deliv Rev. 2001;48(2-3):139-157.

20. Adebowale AA, Adegoke MT, Sanni SA, Adegunwa MO, Fetuga OA. Functional properties and biscuit-making potentials of sorghum wheat-flour composite. Amer J Food Technol. 2012;7(6):372-379.

21. Williams PA, Phillips GO, eds. Gums and Stabilizers for the Food Industry. 12 ${ }^{\text {th }}$ ed. Cambridge, UK: Royal Society of Chemistry; 2004. ISBN 0-85404-891-X.

22. Akin-Ajani OD, Ajala TO, Ikehin M. Date mucilage as co-polymer in metformin-loaded microbeads for controlled release. J Excipients Food Chem. 2019;10(1):3-12.

23. Prasanth VV, Akash CM, Sam TM, Rinku M. Microspheres: An overview. Intern J Pharm Biomed Scs. 2011;2(2):332-338.

24. Poovi G, Arul J, Deepa J, Lakshmi S, Arun D. Review on microspheres. Amer J Drug Discov Dev. 2014;4:153-179.

25. Huynh CT, Lee DS. Controlled release. In: Kobayashi S, Müllen K, eds. Encyclopedia of Polymeric Nanomaterials. Berlin-Heidelberg, Germany: Springer Verlag; 2014. doi:10.1007/978-3-642-36199-9_314-1

26. Odeku OA, Lamprecht A, Okunlola A. Characterization and evaluation of four natural gums as polymers in formulations of diclofenac sodium microbeads. Int J Biol Macromol. 2013;58:113-120. 